\title{
Influence of Age and Anti-platelet/Anti-coagulant Use on the Outcome of Elderly Patients With Fall-Related Traumatic Intracranial Hemorrhage
}

\author{
Joji INAMASU*,**, Masashi NAKATSUKASA*, Takumi KURAMAE*, \\ Yuh NAKAGAWA*, Satoru MIYATAKE**, and Kazuhiro TOMIYASU*** \\ Departments of * Neurosurgery, ${ }^{* *}$ Emergency Medicine, and \\ ***Neurology, Saiseikai Utsunomiya Hospital, Utsunomiya, Tochigi
}

\begin{abstract}
Ground-level fall is the most common cause of traumatic intracranial hemorrhage (TICH) in the elderly. Many studies on geriatric TICH have regarded patients aged $\geq 65$ years as a single group, but substantial heterogeneity is likely to exist within this population. Eighty-two elderly patients with fall-related TICH treated in our institution during a 6-year period were stratified into 3 age groups $(65-74,75-84$, and $\geq 85$ years), and intergroup differences in the demographics and outcomes at discharge were evaluated. The influence of the use of anti-platelet/anti-coagulant (AP/AC) agent on outcomes was also investigated. Comparison of demographic variables demonstrated significant differences in the frequency of preinjury alcohol consumption and use of AP/AC agents between the 3 groups, indicating that the causes or triggers of fall might be substantially different between the 65-74 years group and the other two groups combined. The frequency of unfavorable outcomes increased with age, and the increase was statistically significant. The 82 patients were divided into two subgroups depending on the use of AP/AC agents. The outcomes of the $\geq 85$ years group taking AP/AC agents were particularly poor compared with those of the $\geq 85$ years group not using AP/AC agents. Advancing age may be associated with unfavorable outcomes in elderly patients with fall-related TICH, and patients aged $\geq 85$ years taking $\mathrm{AP} / \mathrm{AC}$ have the greatest risk of unfavorable outcomes. Physicians must consider the risk/benefit analysis before prescribing AP/AC agents to patients aged $\geq 85$ years.
\end{abstract}

Key words: age, anti-coagulant, anti-platelet, elderly, traumatic intracranial hemorrhage

\section{Introduction}

Ground-level fall is the most common cause of traumatic intracranial hemorrhage (TICH) in the elderly, in up to $60-80 \%$ of geriatric patients with TICH, and is frequently associated with high morbidity and mortality. ${ }^{1,8,11,12,16)}$ In general, ground-level fall is categorized as low energy trauma in terms of injury severity. ${ }^{1,8,11,12,17)}$ Currently, the chronological age of 65 years or older is defined as "elderly" according to the Ministry of Health, Labour and Welfare. ${ }^{10)}$ Many clinical studies of geriatric TICH have regarded patients aged $\geq 65$ years as a single homogeneous group, ${ }^{2,5,6)}$ and few studies have considered the possible heterogeneity within the population., ${ }^{4,11,12)}$ However, the demographic characteristics as well as clinical outcomes are likely to differ substantially between hexagenarians and octogenarians after fall-

Received April 20, 2010; Accepted August 30, 2010 related TICH. In addition, preinjury medication with anti-platelet/anti-coagulant (AP/AC) agents, which are commonly prescribed to treat or prevent cerebro- and cardiovascular diseases, may be associated with unfavorable outcomes in elderly patients with TICH. ${ }^{2-6,9)}$

The present study divided elderly patients with fall-related TICH into 3 age groups according to the Centers for Disease Control and Prevention (CDC) classification, ${ }^{1)}$ and evaluated intergroup differences in the demographics and outcomes at discharge, as well as investigating whether the use of AP/AC agents was associated with unfavorable outcomes.

\section{Patients and Methods}

This retrospective study conducted in a single tertiary referral center included a total of 670 patients aged 65 years or older who visited our emergency 
department (ED) with head injury after sustaining a ground-level fall between January 2003 and December 2008. The patients were divided into 3 age groups: 65 to 74 years, 75 to 84 years, and $\geq 85$ years. This stratification was based on the epidemiologic studies conducted by the CDC.1) Brain computed tomography (CT) was obtained according to the Canadian CT Head Rule. ${ }^{14)}$ Medical records of patients admitted for the treatment of TICH were reviewed thoroughly. Demographic data evaluated were: male:female ratio, mean Glasgow Coma Scale (GCS) score, presence of midline shift (MLS) $\geq 5 \mathrm{~mm}$ on CT, presence of skull fracture, alcohol consumption shortly before fall, use of AP/AC agent, surgical intervention, and use of blood-derived products. Outcomes were evaluated with the Glasgow Outcome Scale (GOS) at discharge. ${ }^{7)}$ GOS score of 1 to 3 and GOS score of 4 and 5 were defined as unfavorable and favorable outcomes, respectively. The frequency of patients with unfavorable outcomes was compared between the 3 groups.

Patients with CT evidence of TICH were normally admitted to the intensive care unit or neurosurgical observation unit. Emergency surgery was considered for patients with TICH and MLS $\geq 5 \mathrm{~mm}$, unless they presented with irreversible signs of brain herniation. Surgery was performed only if consent was obtained from the patient's family members. For patients taking warfarin, the only oral AC agent available in Japan, intravenous vitamin $K$ was administered routinely in the ED. Blood-derived products such as fresh frozen plasma or platelet concentrate were used to reverse the adverse effects of warfarin or AP agents only in patients who underwent surgery. Factor IX complex was not used routinely to treat for patients with TICH in our institu- tion.

Statistical analyses were performed using Statmate III (Nihon 3B Scientific, Inc., Niigata, Japan). Continuous variables were compared using the Kruskal-Wallis test, and categorical variables using the chi-square test. Trend for increase was analyzed with the Cochrane-Armitage test. ${ }^{15)} \mathrm{P}<0.05$ was considered statistically significant.

\section{Results}

During the 6-year period, the numbers of elderly patients who visited our ED for the treatment of head injury after sustaining a ground-level fall were 242 for the 65-74 years group, 266 for the 75-84 years group, and 162 for the $\geq 85$ years group. Among these 670 patients, 82 elderly patients were diagnosed with fall-related TICH and admitted to our institution: 27 in the 65-74 years group, 36 in the 75-84 years group, and 19 in the $\geq 85$ years group. The frequency of fall-related TICH did not different significantly between the 3 age groups (Table 1). The male:female ratio, mean GCS score, presence of MLS $\geq 5 \mathrm{~mm}$, presence of skull fracture, surgical intervention, and use of blood-derived products did not differ significantly between the 3 age groups. There was a significant difference in the frequency of preinjury alcohol consumption $(p=0.005)$ as well as use of AP/AC agents $(p=0.009)$ between the 3 groups.

The outcomes of the 82 patients were GOS 1 in 21 patients, GOS 3 in 11 patients, GOS 4 in 22 patients, and GOS 5 in 28 patients. No patients were discharged with GOS 2. The frequencies of unfavorable outcomes at discharge were $26 \%$ in the $65-74$ years group, $36 \%$ in the $75-84$ years group, and $63 \%$ in the

Table 1 Demographic variables of 82 elderly patients ( $\geq 65$ years of age) admitted for fall-related traumatic intracranial hemorrhage (TICH)

\begin{tabular}{|c|c|c|c|c|}
\hline & \multicolumn{3}{|c|}{ Age group } & \multirow{2}{*}{$\mathrm{p}$ Value } \\
\hline & $65-74$ yrs $(n=27)$ & $75-84$ yrs $(n=36)$ & $\geq 85 \operatorname{yrs}(n=19)$ & \\
\hline Incidence of TICH & $27 / 242(11 \%)$ & $36 / 266(14 \%)$ & $19 / 162(12 \%)$ & 0.70 \\
\hline Sex, male:female & $17: 10$ & $16: 20$ & $8: 11$ & 0.41 \\
\hline GCS, mean \pm SD & $11.9 \pm 3.4$ & $12.7 \pm 3.5$ & $10.4 \pm 4.6$ & 0.36 \\
\hline Skull fracture & $12(44 \%)$ & $9(25 \%)$ & $5(26 \%)$ & 0.37 \\
\hline Midline shift $\geq 5 \mathrm{~mm}$ & $7(26 \%)$ & $8(22 \%)$ & $7(37 \%)$ & 0.69 \\
\hline Alcohol consumption before fall & $11(41 \%)$ & $3(8 \%)$ & $1(5 \%)$ & $0.005^{*}$ \\
\hline Use of $\mathrm{AP} / \mathrm{AC}$ agents & $5(19 \%)$ & $21(58 \%)$ & $11(58 \%)$ & $0.009^{*}$ \\
\hline Ratio of AP/AC agents & $4: 1$ & $14: 7$ & $7: 4$ & N/A \\
\hline Surgical intervention & $5(19 \%)$ & $2(6 \%)$ & $0(0 \%)$ & 0.20 \\
\hline Use of blood-derived products & $2(7 \%)$ & $2(6 \%)$ & $0(0 \%)$ & 0.87 \\
\hline
\end{tabular}

*Statistically significant. AP/AC: anti-platelet/anti-coagulant, GCS: Glasgow Coma Scale, N/A: not available. 


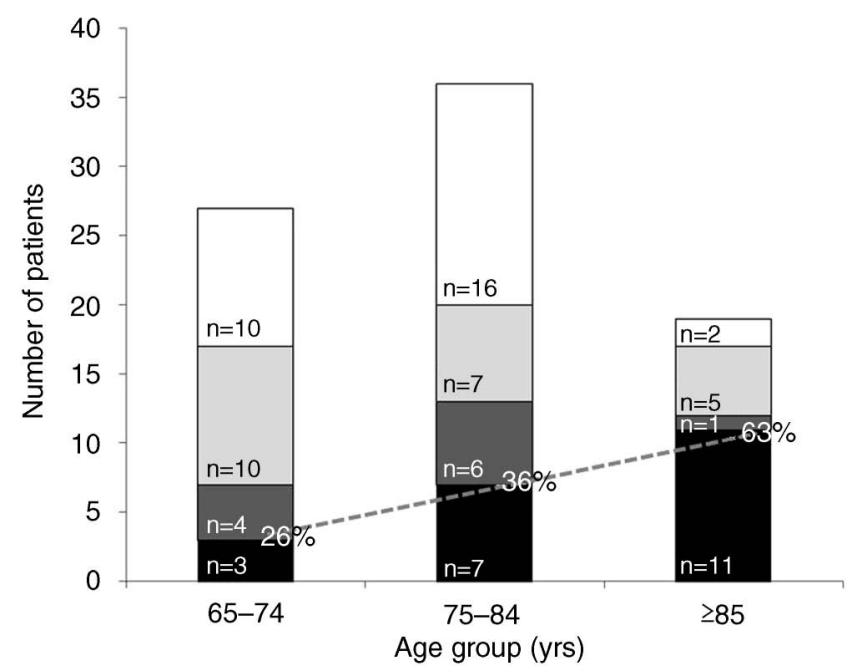

Fig. 1 Bar graphs showing the frequency of unfavorable outcomes in the age groups of the 82 patients with fall-related traumatic intracranial hemorrhage. White figure in each bar indicates the percentage of patients with unfavorable outcomes. The increase in the frequency of unfavorable outcomes is statistically significant (Cochrane-Armitage trend test, $p=0.01$, broken line). $\square$ : Glasgow Outcome Scale (GCS) 5 (good recovery), $\square$ : GOS 4 (moderate disability), $\square$ : GOS 3 (severe disability), $\square$ : GOS 1 (death).

$\geq 85$ years group (Fig. 1). The increase in the frequency of unfavorable outcomes with age was statistically significant ( $\mathrm{p}=0.01)$.

The 82 patients were divided into the two groups according to the preinjury use of AP/AC agents. Among the AP/AC subgroup ( $\mathrm{n}=37$ ), the frequency of unfavorable outcomes at discharge was $40 \%$ in the $65-74$ years group, $38 \%$ in the $75-84$ years group, and $82 \%$ in the $\geq 85$ years group (Fig. 2). The increase in the frequency of unfavorable outcomes was statistically significant $(p=0.04)$. Among the non-AP/AC subgroup ( $\mathrm{n}=45$ ), the frequencies of unfavorable outcomes at discharge were $23 \%$ in the 65-74 years group, $33 \%$ in the $75-84$ years group, and $38 \%$ in the $\geq 85$ years group (Fig. 3 ). The increase in the frequency of unfavorable outcomes was not statistically significant $(p=0.37)$.

The frequency of unfavorable outcomes was compared between the users and non-users of AP/AC agents in each age group. The frequencies of unfavorable outcomes did not differ significantly between users and non-users in the 65-74 and 75-84 years groups (Table 2). However, the frequency of unfavorable outcomes tended to be higher in users compared with non-users in the $\geq 85$ years group, although the difference was not statistically significant $(82 \%$ vs. $38 \%, p=0.07)$.

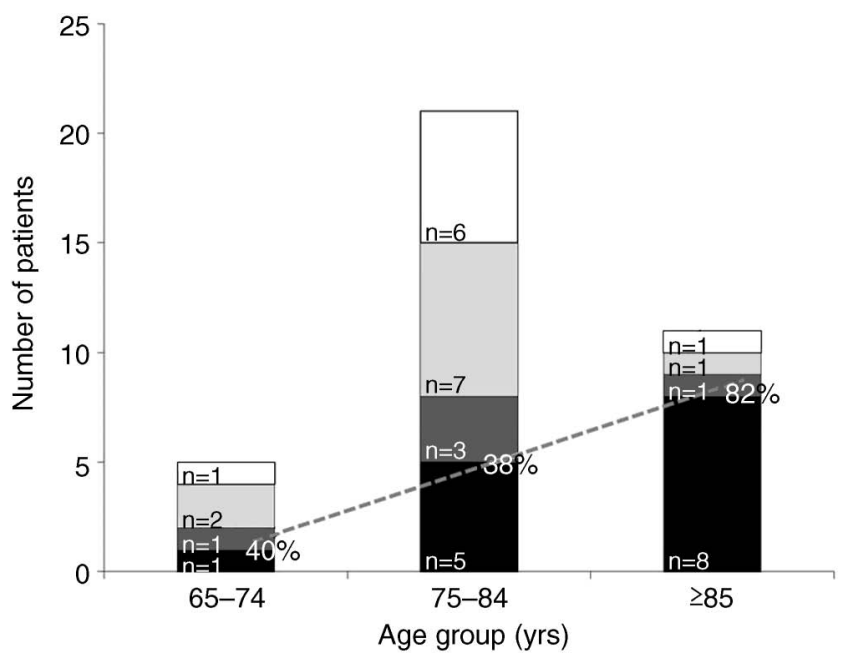

Fig. 2 Bar graphs showing the frequency of unfavorable outcomes in the age groups of the 37 patients with fall-related traumatic intracranial hemorrhage using anti-platelet/anti-coagulant agents. The increase in the frequency of unfavorable outcomes is statistically significant (Cochrane-Armitage trend test, $p=0.04$, broken line). $\square$ : Glasgow Outcome Scale (GCS) 5 (good recovery), $\square$ : GOS 4 (moderate disability), $\square$ : GOS 3 (severe disability), $\square$ : GOS 1 (death).

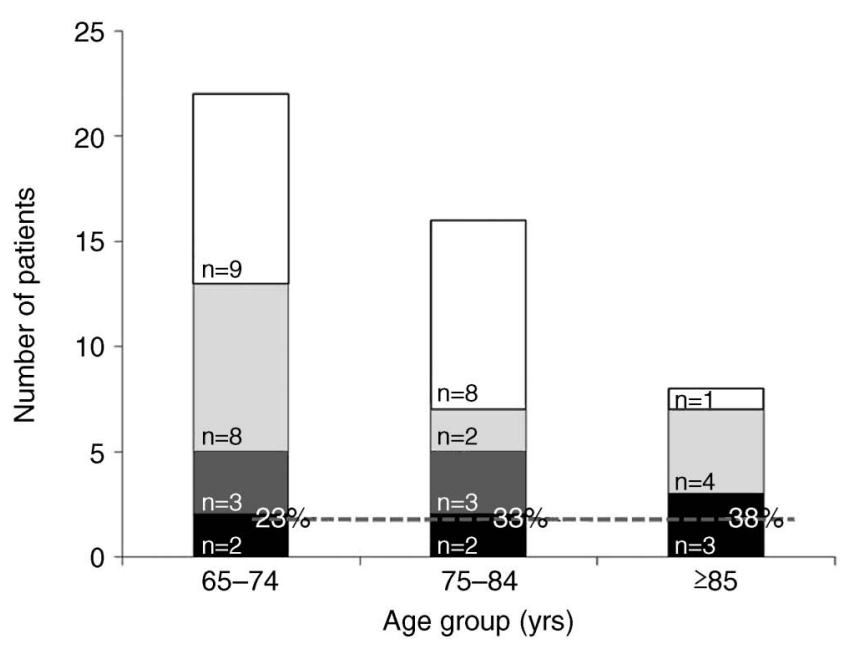

Fig. 3 Bar graphs showing the frequency of unfavorable outcomes in the age groups of the 45 patients with fall-related traumatic intracranial hemorrhage not using anti-platelet/anti-coagulant agents. The increase in the frequency of unfavorable outcomes is not statistically significant (Cochrane-Armitage trend test, $p=0.37$, broken line). $\square$ : Glasgow Outcome Scale (GCS) 5 (good recovery), $\square$ : GOS 4 (moderate disability), $\square$ : GOS 3 (severe disability), $\square$ : GOS 1 (death). 
Table 2 Frequency of patients with unfavorable outcomes, classified by age and use of anti-platelet/anticoagulant (AP/AC) agents

\begin{tabular}{lccc}
\hline \multirow{2}{*}{ Use of AP/AC } & \multicolumn{3}{c}{ Age group } \\
\cline { 2 - 4 } & $65-74$ yrs & $75-84$ yrs & $\geq 85 \mathrm{yrs}$ \\
\hline Users & $2 / 5(40 \%)$ & $8 / 21(38 \%)$ & $9 / 11(82 \%)$ \\
Non-users & $5 / 22(23 \%)$ & $5 / 15(33 \%)$ & $3 / 8(38 \%)$ \\
\hline p Value (chi-square) & 0.58 & 0.95 & 0.07 \\
\hline
\end{tabular}

\section{Discussion}

Comparison of demographic variables between the 3 age groups revealed significant differences in the frequency of preinjury alcohol consumption as well as use of AP/AC agents. These findings indicate that the causes or triggers of ground-level fall may be substantially different between the 65-74 years group and the other two groups. Nevertheless, the preinjury intake of alcohol may not be associated with unfavorable outcomes, which is compatible with previous reports. ${ }^{5)}$ The presence of skull fracture, mean GCS score, MLS $\geq 5 \mathrm{~mm}$, surgical intervention, and the use of blood-derived products were not significantly different between the 3 groups (Table 1).

Figure 1 demonstrated a significant increase in the frequency of unfavorable outcomes with advancing age by the Cochrane-Armitage test, which check$\mathrm{s}$ for trend in binomial proportions across levels of a single factor or covariate. ${ }^{15)}$ These findings are easily understandable, but have been little reported. Our subgroup analysis found that the increase in the frequency of unfavorable outcomes with advancing age was present in users of AP/AC agents, but not in non-users of AP/AC agents (Figs. 2 and 3). Furthermore, the outcomes of the $\geq 85$ years group using AP/AC agents were particularly poor, compared with either the younger age group using AP/AC agents (Fig. 2) or with the same age group not using AP/AC agents (Table 2).

The benefits of AP/AC agents for preventing cerebro- and cardiovascular adverse events in the elderly are well established, ${ }^{9}$ and the risk of unfavorable outcomes after falls in geriatric patients taking AP/AC agents has been known for years, but the risk/benefit analysis of AP/AC agents in patients aged $\geq 85$ years has been unclear. This study found that patients aged $\geq 85$ years taking AP/AC agents had the highest risk of unfavorable outcomes after sustaining fall-related TICH, indicating that physicians should carefully consider the risk/benefit anal- ysis before prescribing AP/AC agents to patients aged $\geq 85$ years.

This retrospective study has several limitations. First, the reasons for the particularly poor outcomes of the $\geq 85$ years group taking AP/AC agents remain to be identified. The subgroup analysis showed that the frequency of MLS $\geq 5 \mathrm{~mm}$ was highest and mean GCS score was lowest in the $\geq 85$ years group taking AP/AC agents (data not shown), so that these patients probably fared worst because they most frequently sustained a life-threatening form of TICH. In fact, the great majority of patients with unfavorable outcomes in the $\geq 85$ years group taking AP/AC agents died of brain death shortly after injury (data not shown). Second, we intentionally refrained from analyzing the effect of surgical intervention on the outcomes, since surgery was often declined by family members, particularly if the elderly patient had underlying debilitating conditions or dementia. In retrospect, some of the patients who died without surgical intervention might have been saved if permission to perform surgery had been granted, so we were concerned that the analysis would be confounded or biased. For the same reason, the use of blood-derived products, which are rarely used in our institution, was not evaluated fully. Although the aggressive use of such products might have changed outcomes to some extent, the efficacy remains unproven by the evidence. ${ }^{2,9)}$ Third, the adverse effects of AP and AC agents may differ substantially in geriatric patients with TICH. Warfarin is known to have unfavorable effects, but whether the use of AP agents is associated with unfavorable outcomes remains controversial. ${ }^{2-6,12,13)}$ Therefore, the adverse effects of AP and AC agents must be evaluated separately in future studies. We combined AP and AC agents mainly because of the small number of patients in each age group. Nevertheless, the various AP agents have different biological and pharmacological profiles, including aspirin, clopidogrel, and cilostazol, so heterogeneity within the AP category may also have to be considered.

Despite these limitations, we expect that the results of this study will be appreciated both by neurosurgeons who take care of injured elderly patients and by primary care physicians who prescribe AP/AC agents. Undoubtedly, prevention is the most effective measure to reduce the frequency of fallrelated TICH. Dissemination of evidence about fall prevention, coupled with medical interventions, is expected to reduce fall-related injuries in that vulnerable population. ${ }^{16)}$ 


\section{References}

1) Coronado VG, Thomas KE, Sattin RW, Johnson RL: The CDC traumatic brain injury surveillance system: characteristics of persons aged 65 years and older hospitalized with a TBI. J Head Trauma Rehabil 20: 215-228, 2005

2) Downey DM, Monson B, Butler KL, Fortuna GR Jr, Saxe JM, Dolan JP, Markert RJ, McCarthy MC: Does platelet administration affect mortality in elderly head-injured patients taking antiplatelet medications? Am Surg 75: 1100-1103, 2009

3) Fortuna GR, Mueller EW, James LE, Shutter LA, Butler KL: The impact of preinjury antiplatelet and anticoagulant pharmacotherapy on outcomes in elderly patients with hemorrhagic brain injury. Surgery 144: 598-603, 2008

4) Franko J, Kish KJ, O'Connell BG, Subramanian S, Yuschak JV: Advanced age and preinjury warfarin anticoagulation increase the risk of mortality after head trauma. J Trauma 61: 107-110, 2006

5) Gangavati AS, Kiely DK, Kulchycki LK, Wolfe RE, Mottley JL, Kelly SP, Nathanson LA, Abrams AP, Lipsitz LA: Prevalence and characteristics of traumatic intracranial hemorrhage in elderly fallers presenting to the emergency department without focal findings. J Am Geriatr Soc 57: 1470-1474, 2009

6) Howard JL 2nd, Cipolle MD, Horvat SA, Sabella VM, Reed JF 3rd, Fulda G, Tinkoff G, Pasquale MD: Preinjury warfarin worsens outcome in elderly patients who fall from standing. J Trauma 66: 1518-1522, 2009

7) Jennett B, Teasdale G, Braakman R, Minderhoud J, Heiden J, Kurze T: Predicting outcome in individual patients after severe head injury. Lancet 1: 1031-1034, 1976

8) Kennedy RL, Grant PT, Blackwell D: Low-impact falls: demands on a system of trauma management, prediction of outcome, and influence of comorbidities. J Trauma 51: 717-724, 2001

9) McMillian WD, Rogers FB: Management of prehospital antiplatelet and anticoagulant therapy in traumatic head injury: a review. J Trauma 66: 942-950, 2009
10) Ministry of Health, Labour and Welfare Japan: [Vital statistics], in: [White Paper on Health, Labour and Welfare]. Tokyo, Gyosei Corp, 2009, pp 38-42 (Japanese)

11) Nagurney JT, Borczuk P, Thomas SH: Elderly patients with closed head trauma after a fall: mechanisms and outcomes. J Emerg Med 16: 709-713, 1998

12) Sarani B, Temple-Lykens B, Kim P, Sonnad S, Bergey M, Pascual JL, Sims C, Schwab CW, Reilly P: Factors associated with mortality and brain injury after falls from the standing position. J Trauma 67: 954-958, 2009

13) Spektor S, Agus S, Merkin V, Constantini S: Lowdose aspirin prophylaxis and risk of intracranial hemorrhage in patients older than 60 years of age with mild or moderate head injury: a prospective study. J Neurosurg 99: 661-665, 2003

14) Stiell IG, Wells GA, Vandemheen K, Clement C, Lesiuk H, Laupacis A, McKnight RD, Verbeek R, Brison R, Cass D, Eisenhauer ME, Greenberg G, Worthington J: The Canadian CT Head Rule for patients with minor head injury. Lancet 357: 1391-1396, 2001

15) Timaran $\mathrm{CH}$, Rosero EB, Smith ST, Valentine RJ, Modrall JG, Clagett GP: Trends and outcomes of concurrent carotid revascularization and coronary bypass. J Vasc Surg 48: 355-360, 2008

16) Tinetti ME, Baker DI, King M, Gottschalk M, Murphy TE, Acampora D, Carlin BP, Leo-Summers L, Allore HG: Effect of dissemination of evidence in reducing injuries from falls. $N$ Engl $J$ Med 359: 252-261, 2008

17) Velmahos GC, Jindal A, Chan LS, Murray JA, Vassiliu P, Berne TV, Asensio J, Demetriades D: "Insignificant" mechanism of injury: not to be taken lightly. J Am Coll Surg 192: 147-152, 2001

Address reprint requests to: Joji Inamasu, M.D., Ph.D., Department of Neurosurgery, Saiseikai Utsunomiya Hospital, 911-1 Takebayashi, Utsunomiya, Tochigi 321-0974, Japan.

e-mail: ginamasu@aol.com 